Chapman University

Chapman University Digital Commons

ESI Publications

Economic Science Institute

6-18-2018

Land Assembly with Taxes, Not Takings

Mark DeSantis

Matthew W. McCarter

Abel Winn

Follow this and additional works at: https://digitalcommons.chapman.edu/esi_pubs

Part of the Economic Theory Commons, and the Other Economics Commons 


\section{Land Assembly with Taxes, Not Takings}

\section{Comments}

This is an Accepted Manuscript of an article published in Applied Economics Letters, volume 26, issue 7, in 2018, available online at DOI: $10.1080 / 13504851.2018 .1488047$. It may differ slightly from the final version of record.

\section{Copyright}

Taylor \& Francis 


\title{
Land Assembly with Taxes, Not Takings
}

\author{
Mark DeSantis \\ Chapman University \\ One University Dr. \\ Orange, CA 92866 \\ desantis@chapman.edu \\ (714) 997-6957 \\ Matthew W. McCarter \\ University of Texas - San Antonio \\ One UTSA Circle \\ San Antonio, TX 78249 \\ Matthew.McCarter@utsa.edu \\ (210)488-0455 \\ Abel M. Winn ${ }^{1}$ \\ Chapman University \\ One University Dr. \\ Orange, CA 92866 \\ winn@ chapman.edu \\ (714) 744-7986
}

Forthcoming in Applied Economics Letters.

\begin{abstract}
We use a novel tax mechanism - "rejected offer reassessment" - in laboratory experiments to discourage seller holdout and facilitate land assembly. Under this mechanism if a landowner rejects a developer's offer his taxable property value is reassessed to be equal to the rejected offer, increasing his taxes. We find that, relative to a control treatment, rejected offer reassessment discourages the magnitude of seller holdout (but not its frequency) and increases the rate of successful land assembly by almost $60 \%$. It also increases the gains from trade by $22.1 \%$ relative to the control treatment, but the difference is not statistically significant.
\end{abstract}

Keywords: Land assembly, holdout, taxation, real estate

JEL Codes: H20, K34, R52

Funding: This research was supported by the Mercatus Center

\footnotetext{
${ }^{1}$ Corresponding author.
} 


\section{Data Availability}

The data that support the findings of this study are available from the corresponding author, AW, upon reasonable request.

\section{Disclosure}

The authors of this paper received a research grant from the Mercatus Center. The grant was for a total of $\$ 7,500$, of which each author received $\$ 2,500$ as a stipend. $50 \%$ of this stipend was paid upon submitting an initial draft of the research findings. The remaining $50 \%$ was paid once the final draft was accepted after a round of peer review.

The Mercatus Center had no financial or professional interest in the results of the experiments presented in this paper. Moreover, the authors pre-registered their hypotheses and statistical design with the Center in advance. We therefore declare no conflict of interest with the Mercatus Center.

Doug \& Marion Lee gave one of the authors, AW, a gift of $\$ 250$ for his professional use. This money was used to defray the expenses of participant payments. Mr. \& Mrs. Lee are retired and not interested parties. AW and MD paid for the remaining participant earnings from their research budgets at Chapman University. 


\section{Introduction}

DeSantis, McCarter \& Winn (2017) tested two self-assessment tax mechanisms to facilitate land assembly when properties are complementary inputs to a development project. ${ }^{2}$ The mechanisms achieved successful assembly in $83.3 \%$ of negotiations, capturing more than $90 \%$ of the available surplus. However, self-assessment taxation may be politically unpopular because it binds a landowner to sell at his self-assessed price.

We consider an alternative tax mechanism, "rejected offer reassessment" (ROR). Under ROR - proposed by Miceli, Segerson \& Sirmans (2008) - if a landowner rejects a developer's offer the government takes the offer as a lower bound on his subjective value for the property and reassesses the taxable value of the property at the rejected offer. Thus, strategic holdout is costly for landowners and successful assembly is promoted.

We conduct laboratory experiments to test the efficacy of ROR at discouraging holdout and facilitating land assembly. We find that, compared to a control treatment, ROR increases the assembly rate by $58.4 \%$ and the gains from trade by $22.1 \%$. The effect on assembly is statistically significant, but the effect on gains from trade is not.

\section{Experiment Design}

We conducted experiments for one control (Baseline) and one experimental treatment (ROR). Our experimental design for Baseline follows DeSantis, McCarter \& Winn (2017), and we refer the reader to that paper for a detailed description. Each treatment consisted of 30 negotiations conducted in three sessions with 10 negotiations each.

\footnotetext{
${ }^{2}$ Holdout has been observed in laboratory experiments by, e.g., Cadigan, Schmitt, Shupp, \& Swope (2009, 2011), Swope, Wielgus, Schmitt \& Cadigan (2011), Parente \& Winn (2012), Collins \& Isaac (2012), Zillante, Schwarz, \& Read (2014), Swope, Cadigan \& Schmitt (2014) and Winn \& McCarter (2017). Brooks \& Lutz (2016) and Portillo (2017) report field data consistent with seller holdout.
} 
Negotiation proceeded in groups of five participants: one developer (buyer) and four landowners (sellers). The sellers were assigned values for their property, while the buyer was assigned a value for the combination of all four properties. Values were denominated in Economic Currency Units (ECU, denoted “\$”). Sellers (Buyers) received \$1 US for $\$ 16,500(\$ 60,000)$ ECU. The exchange rates were private information.

All values were drawn from uniform distributions and rounded to the nearest thousand. The sellers' (buyer's) distribution had support $[\$ 100,000, \$ 150,000]$ ([\$300,000, $\$ 1,250,000])$. These distributions were common knowledge, but the participants' value draws were private information. Sellers earned their values for the property minus tax if they did not sell, or the price at which they sold if they did.

The buyer was endowed with $\$ 350,000$, which served as an opportunity cost to negotiating. The amount of cash was private information, but its existence was common knowledge. If the buyer refused to negotiate she kept the cash. If a buyer assembled four properties she earned her value plus the cash endowment minus the sum of the prices she paid minus property tax. If a buyer assembled fewer than four properties she paid the sellers who accepted her offers, but sold the properties to the experimenter for $\$ 100,000$ each.

We randomly generated buyer and seller values for 30 negotiations and used the same value draws in both treatments. Assembly was efficient in $24(80 \%)$ of the negotiations, which we call the "positive-sum" negotiations. The minimum, maximum and average available gains from trade in these negotiations were $\$ 5,000, \$ 765,000$ and $\$ 379,000$.

Negotiations proceeded for up to five rounds, with three phases each: 
- Phase one: Sellers communicated via text chat, after which they each sent a nonbinding price request to the buyer. Phase one lasted for seven minutes in the first round and two minutes in subsequent rounds.

- Phase two: The buyer observed the price requests and chose to either abandon the negotiation or simultaneously send binding offers to the sellers. The buyer could offer different amounts to different sellers, but the sum of the offers could not exceed her value plus her cash.

- Phase three: Sellers observed the offers and chose to accept or reject them. They had one minute to communicate with one another before submitting their decision.

If a seller rejected his offer negotiations continued to phase one of the next round. If a seller accepted his offer the price at which he sold was disclosed to all sellers. A seller who accepted an offer was not allowed to chat with the other sellers or see their text messages in subsequent rounds. He could click a button on his user interface to launch Microsoft Paint. We included this function to prevent sellers from extending negotiations to stave off boredom.

All properties had a $\$ 100,000$ assessed value. $10 \%$ of the assessed value was collected from the owner of the property at the end of negotiations. (A buyer who purchased fewer than four properties sold them to the experimenter and so was not liable for tax.) Reassessment on sale is the status quo in most US jurisdictions. In Baseline properties were reassessed upon sale, so sellers who kept their property paid $\$ 10,000$ in tax. In $R O R$ unsold properties were reassessed at the end of a negotiation according to the highest rejected offer. For instance, if a seller rejected offers of $\$ 120,000, \$ 135,000$ and $\$ 130,000$ in rounds one through three and the buyer then abandoned negotiations, the seller's property would be reassessed at $\$ 135,000$, and the seller would owe $\$ 13,500$ in tax. 
Prolonged negotiations were costly to the buyer. The cost took the form of a multiplier applied to the buyer's earnings after the negotiation. The multiplier was $100 \%$ if the negotiation ended in round one. It decreased to $95 \%$ in round $2,90 \%$ in round 3, etc. The multiplier was $75 \%$ if the buyer had not assembled all four properties (or abandoned negotiations) after round five.

\section{Results}

Finding 1: ROR did not reduce the frequency of holdout, but did reduce its magnitude.

Support: We measured holdout by subtracting each seller's tax-adjusted value from the highest offer they rejected. Positive differences indicate holdout, and the value of the difference measures the magnitude of holdout. In Baseline $48.3 \%$ of sellers rejected an offer exceeding their tax-adjusted value; in $R O R$ it was $51.7 \%$. However, among sellers who did hold out, the average difference between the highest rejected offer and the seller's value was $\$ 53,701.74$ in Baseline and $\$ 26,453.76$ in $R O R$; a $48.1 \%$ reduction.

We test for treatment effects in holdout frequency and magnitude using a logistic regression for holdout $(1=$ yes, $0=$ no) and an OLS regression for holdout magnitude (Table 1$) .^{3}$ The logistic regression only includes observations from sellers who received an offer and the OLS regression only includes observations from sellers who held out. Both models control for treatment, negotiation number and the seller's tax-adjusted value. Standard errors are clustered by group. In the logistic regression the estimated coefficient for ROR is not significant $(p=0.872)$. The OLS regression estimates the magnitude of holdout was $\$ 28,024$ less in ROR than in Baseline, and the

\footnotetext{
${ }^{3}$ A Heckman selection model found no significant correlation between the error terms of the frequency and magnitude models $(\rho=-0.05$, S.E. $=0.07,95 \%$ C.I. $=-0.18$ to 0.08$)$. Thus, we estimate the models separately for ease of interpretation.
} 
Table 1. Estimates on holdout frequency and magnitude.

\begin{tabular}{lcc}
\hline & $\begin{array}{c}\text { Logistic Regression on } \\
\text { Holdout Frequency }\end{array}$ & $\begin{array}{c}\text { OLS Regression on Holdout } \\
\text { Magnitude }\end{array}$ \\
\hline Variable & $\begin{array}{c}\text { Coefficient } \\
\text { (Std. Err.) }\end{array}$ & $\begin{array}{c}\text { Coefficient } \\
\text { (Std. Err.) }\end{array}$ \\
\hline Constant & 0.88 & 59,037 \\
ROR & $(1.41)$ & $(40,767)$ \\
Negotiation Number & 0.05 & $-28,024^{*}$ \\
& $(0.34)$ & $(13,042)$ \\
Seller's Value (in \$10,000s) & 0.61 & 14,048 \\
& $(0.35)$ & $(11,686)$ \\
\hline Observations & -0.13 & $-2,187$ \\
Pseudo R & $(0.10)$ & $(2,582)$ \\
Wald $^{2}$ & 220 & 120 \\
$\mathrm{R}^{2}$ & 0.023 & -- \\
F-Statistic & 4.02 & -- \\
${ }^{*}$ Significant at 5\% & -- & 0.113 \\
\end{tabular}

effect is significant $(p=0.037)$. Relative to the estimated constant of $\$ 59,037$ this represents a reduction in holdout magnitude of $47.5 \%$.

Finding 2: ROR increased the rate of assembly.

Support: In Baseline buyers assembled all four properties in 50\% of the positive-sum negotiations. In $R O R$ the assembly rate was $79.2 \%$, a $58.4 \%$ increase. We test for statistical significance with a logistic regression on a binary variable indicating assembly $(1=$ success, $0=$ failure), controlling for treatment, negotiation number and amount of available surplus (in $\$ 10,000$ s) (See Table 2). We limit the dataset to observations from the positive-sum negotiations.

The estimated coefficient for $R O R$ is positive and significant $(p=0.033)$. Assuming the available surplus is the mean observed $(\$ 379,000)$ and participants are in their first negotiation, 
Table 2. Estimates from logistic regression on successful assembly in positive-sum negotiations.

\begin{tabular}{lc}
\hline Variable & $\begin{array}{c}\text { Coefficient } \\
\text { (Std. Err.) }\end{array}$ \\
\hline Constant & -0.61 \\
& $(1.18)$ \\
& $1.46^{*}$ \\
Negotiation Number & $(0.69)$ \\
& -0.46 \\
Available Surplus & $(0.68)$ \\
(in \$10,000s) & 0.03 \\
\hline Observations & $(0.02)$ \\
Pseudo R ${ }^{2}$ & 48 \\
Wald $\chi^{2}$ & 0.138 \\
* Significant at 5\% & 8.63 \\
\hline
\end{tabular}

the model estimates the Baseline probability of assembly at $55.4 \%$ compared to $84.3 \%$ in $R O R$ an increase of $52.2 \%$.

Buyers could ensure that it was in a seller's financial interest to sell by making an offer greater than his maximum tax-adjusted value: $\$ 140,000$ in Baseline and $\$ 136,363$ in ROR. Sellers in Baseline rejected $65.5 \%$ of such offers; sellers in $R O R$ rejected $51.7 \%$. Moreover, sellers requested approximately $\$ 199,000$ on average in Baseline, compared to $\$ 164,000$ in $R O R$. Seller recalcitrance led buyers in Baseline to quit negotiating early in $25 \%$ of the positive-sum negotiations compared to $4.2 \%$ in $R O R$.

Finding 3: ROR did not increase the gains from trade.

Support: We measure the social welfare as the surplus captured through negotiation. The surplus is defined as the participants' actual earnings minus their earnings had the buyer abandoned negotiations in round one. There was $\$ 9,096,000$ in available surplus in each treatment. 
Table 3. Estimates from OLS regression on normalized surplus.

\begin{tabular}{ll}
\hline Variable & $\begin{array}{l}\text { Coefficient } \\
\text { (Std. Err.) }\end{array}$ \\
\hline Constant & $-58,950$ \\
& $(63,485)$ \\
ROR & 27,322 \\
& $(38,282)$ \\
Negotiation Number & 39,300 \\
& $(33,589)$ \\
\hline Observations & 60 \\
$\mathrm{R}^{2}$ & 0.027 \\
F-Statistic & 0.78 \\
\hline
\end{tabular}

${ }^{*}$ Significant at $5 \%$

Participants in Baseline captured approximately $\$ 3,700,000(41.1 \%)$ of this. In ROR they captured about $\$ 4,600,000(50.2 \%)$.

For each negotiation we subtracted the surplus that had been captured in Baseline to minimize the variance. We fit these differences as the dependent variable in an OLS regression with a treatment dummy and the negotiation number as regressors. (See Table 3.) The model estimates that participants in ROR captured $\$ 27,322$ more per negotiation than in Baseline, but the effect is not significant $(p=0.478)$.

This null result has two causes. First, ROR did not reduce delay. The average negotiation took 3.8 rounds in Baseline and 3.83 rounds in ROR. Second, the extra assemblies in $R O R$ were in negotiations with less available surplus. Of the $50 \%$ of positive-sum negotiations with the highest available surplus, buyers were successful in two thirds in both Baseline and ROR. Among the remaining positive-sum negotiations the assembly rate was $33.3 \%$ in Baseline and $91.7 \%$ in ROR. 


\section{Conclusion}

We test Miceli, Segerson \& Sirmans' (2008) proposal to facilitate land assembly by reassessing property taxes after a refused offer from a developer. In our laboratory experiments this policy is effective in reducing the amounts for which sellers hold out, and increases the rate of assembly by $58.4 \%$ relative to the status quo. However, the resulting improvement to social welfare is not statistically significant. The self-assessment mechanisms tested by DeSantis, Winn \& McCarter (2017) provide a similar improvement in successful assembly along with large, statistically significant increases in social welfare. Subject to political constraints, these selfassessment mechanisms should be preferred to the re-assessment mechanism evaluated here. 


\section{References}

BROOKS, L. \& LUTZ, B. (2016). “From today's city to tomorrow's city: An empirical investigation of urban land assembly." American Economic Journal: Economic Policy, 8(3), 69-105.

CADIGAN, J., SCHMITT, P., SHUPP, R., \& SWOPE, K. (2009). “An experimental study of the holdout problem in a multilateral bargaining game." Southern Economic Journal, 76(2), 444-457.

CADIGAN, J., SCHMITT, P., SHUPP, R., \& SWOPE, K. (2011). "The holdout problem and urban sprawl: Experimental evidence.” Journal of Urban Economics, 69(1), 72-81.

COLLINS, S. M., \& ISAAC, R. M. (2012). "Holdout: Existence, information, and contingent contracting." Journal of Law and Economics, 55(4), 793-814.

DESANTIS, M., MCCARTER, M. \& WINN, A. (2017). "Land assembly without eminent domain: Laboratory experiments of two tax mechanisms" Working paper. Available at: https://papers.ssrn.com/sol3/papers.cfm?abstract_id=3083158

MICELI, T. J., SEGERSON, K., \& SIRMANS, C. F. (2008). “Tax motivated takings.” National Tax Journal, 61(4), 579-591.

PARENTE, M. D., \& WINN, A. M. (2012). "Bargaining behavior and the tragedy of the anticommons." Journal of Economic Behavior \& Organization, 84(2), 475-490.

PORTILLO, J. (2017). "The impact of bargaining delays under the threat of eminent domain." Journal of Regional Science, DOI: 10.1111/jors.12363

SWOPE, K. J., CADIGAN, J., \& SCHMITT, P. (2014). "That's my final offer! Bargaining behavior with costly delay and credible commitment." Journal of Behavioral and Experimental Economics, 49(1), 44-53.

SWOPE, K. J., WIELGUS, R., SCHMITT, P., \& CADIGAN, J. (2011). “Contracts, behavior, and the land-assembly problem: An experimental study." Research in experimental economics, $14,151-180$.

WINN, A. \& MCCARTER, M. (2017). "Who's holding out? An experimental study of the burdens and benefits of eminent domain." Journal of Urban Economics, Forthcoming. Available at: http://www.sciencedirect.com/science/article/pii/S0094119017300803

ZILLANTE, A., SCHWARZ, P. M., \& READ, D. C. (2014). "Land aggregation using contingent and guaranteed payments." Southern Economic Journal, 80(3), 702-727. 